\title{
PERSPECTIVE
}

\section{One for All and All for One!}

\author{
Karen Denard Goldman
}

Consultant

\author{
"The time has come," the Writer said, \\ "To talk of many things: \\ No boos-no quips_-just all the facts- \\ Of ravages splits bring; \\ And why we must unite at last- \\ If our profession's to take wing."
}

(c) 2004 Californian Journal of Health Promotion. All rights reserved.

Keywords: perspective, health education, health education profession, coalition

But enough of cabbages and kings! Today we're here to talk about elephants and musketeers; getting and communicating the big picture and committing ourselves to that vision!

Remember the wonderful Indian folk story of the five blind men and the elephant? Each one thought that the part of the elephant he was touching (the side, ear, tail, tusk, and trunk) correctly represented the whole elephant...until they were brought together by the local wise man that helped them realize that each had touched only a part of the body of the animal and thus only had a partial view of it. When, under the guidance of the man who had actually seen the elephant, they put their partial views together, they were able to "see" what an elephant looked like.
As I see it, different health education constituencies have hold of the health education elephant by different parts. The time has come, I believe, for leaders with a broad, professionwide vision to help pull together the individual perspectives and perceptions so we can promote a clear, comprehensive, accurate, and united picture of the health education elephant.

How many perceptions are there of the health education elephant? Well, we know that there are about 250 professional preparation programs in the US, and, according to the Department of Labor, about 40,000 (declared - what do you put on your income tax forms as your profession?) health educators in this country. And the last time I looked, there were 11, yes 11, professional health education organizations (see Figure 1).

\footnotetext{
*The American College Health Association (founded in 1920 as the American Student Health Association)

*The American Public Health Association sections on Public Health Education in 1922 (now known as the Public Health Education and Health Promotion Section) and Public School Health Education (founded in 1942, now known as the School Health Education and Services Section)

*The American School Health Association (founded in 1927 as the American Association of School
} 


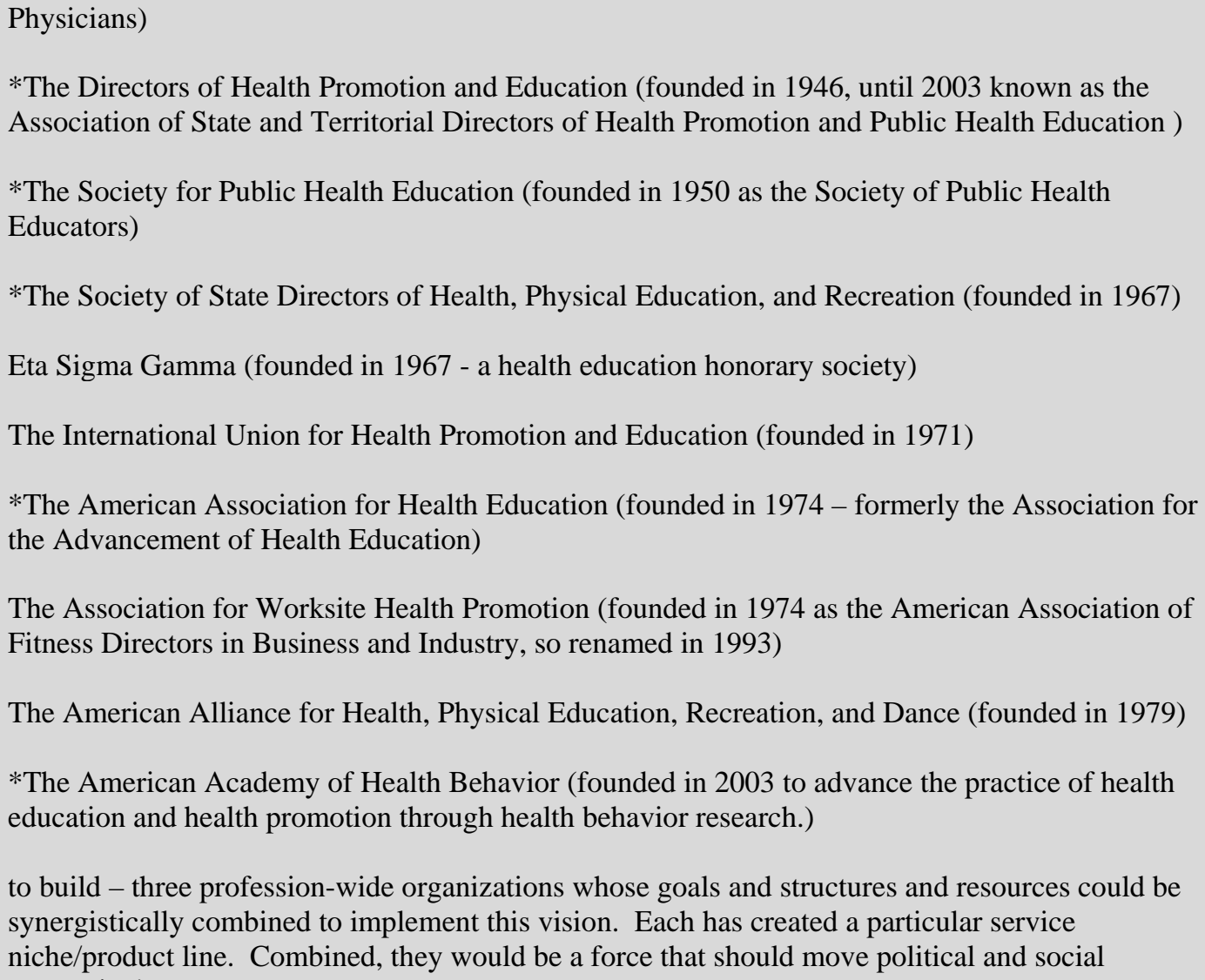

Figure 1

Professional Organizations Representing Health Education/Educators

Each organization has its own perspective of what representing the profession means. And each, consequently, has its own mission statement, computerized administration system and databases, journals, newsletters, web sites, grant application process, list servs, conferences, tasks forces, committees, etc. And each fights mightily for its cause, protecting and promoting its constituency to the best of its abilities.

What if all these profession-defenders and promoters were more like 11 Musketeers?

You remember Dumas' famous story The Three Musketeers - set in 1625 in Paris. Three members of the Elite Guard and one who wants to join are as different as can be - but single-minded in their dedication to protect Louis XIII of France. You remember, "Athos, Porthos, Aramis, and d'Artagnan, forward to the fight! One for all and all for one!"
What I propose is perhaps as dramatic and perhaps romantic - a declaration of interdependence among health education professional organizations and a commitment to profession-wide progress - before any particularly specialty, i.e., school, patient, or public health.

I agree with Ben Franklin: "United we stand, divided we fall."

My prescription for profession-wide falls prevention is a rousing, "All for one and one for all!"

In other words, I propose that the 11 national professional organizations and the National Coalition for Health Education Organization, the National Center for Health Education, and the National Commission for Health Education Credentialing, Inc. (see Figure \#2) combine resources, functions, systems, and perhaps even staff to become one strategic, centralized, financially sustainable health 
education organization (with specialty sections, to be sure!) that will speak and act on behalf of the entire profession.

\section{Firm Foundations Upon Which to Build}

The good news is that there's no need to start from scratch. We have a firm foundation upon which to build - three profession-wide organizations whose goals and structures and resources could be synergistically combined to implement this vision. Each has created a particular service niche/product line. Combined, they would be a force that should move political and social mountains!

In 1972 the Coalition of National Health Education Organizations (NCHEO), made up of representatives of eight national organizations (see asterisks above), was formed "to advance the profession of health education and to foster communication, collaboration and action on issues important to health and health education.” In terms of its accomplishments, here's how I see it. The Coalition sponsored two invitational conferences to assess the status of health education, set goals and make recommendations for the 21st century. Two 21st Century Reports were issued. The NCHEO followed up on this initiative with a series of strategic work groups, but lacks the resources and the authority to do so. The Coalition has supported the campaign to win recognition of the title "health educator" by the federal government as a standard occupation, the annual Health Education Advocacy Summits, and the development of a Health Education Advocate Web site - which is not, unfortunately the one single health education advocacy source representing the entire profession. The NCHEO has also supported the Competencies update project, the joint Task Force on Program Accreditation, and the promotion of National Health Education Week. In its most proactive role, the Coalition ushered through of a profession-wide Code of Ethics based on the initial efforts of two independent health education organizations. Sometimes letters are written on behalf of the profession.

Why can't the NCHEO do more? The problem seems to be a matter of resources, and, in my opinion, the lack of a professional political will. CNHEO has no office and no paid staff; its members rotate on and off; there's no accountability; and, I believe, cooperative actions happen only when the support is unanimous. But is the potential there to build on this structure and enhance it through collaboration with the two other organizations described below? As I see it, you bet there is!

In 1971, the President's Committee on Health Education recommended the creation of an institution to play a leadership role in the private sector in "raising the level of health citizenship." Originally, the National Center for Health Education (NCHE) was envisioned as a flexible, problem-solving mechanism in health education with five core functions: (1) advocacy for health education; (2) convening of health educators; (3) technical assistance for health educators; (4) research and evaluation of health information; and (5) information exchange.

Over the years, NCHE, funded largely by foundations and corporations such as the Kellogg Foundation, the Metropolitan Life Insurance Company, the National Endowment for the Humanities, and the Henry J. Kaiser Family Foundation has worked toward these ends, focusing on child health. 
Its accomplishments include initiating the Health Education Role Delineation Project, assuming national leadership of the School Health Curriculum Project (Growing Healthy), helping to form the National School Health Coalition, published Healthlink magazine, co-sponsoring, with Harvard School of Public health monthly luncheons for members of the media to discuss methods for researching and reporting on health issues, hosting with the Annenberg Center for Health Sciences a national forum addressing ethical issues in advertising of health-related products, designing and sponsoring with the Colgate University InterFraternity Council a forum for parents, caregivers, teachers, administrators, health professionals, and the local community about current health and family issues, focusing on parent/child interaction and improving communication, and becoming the official sponsor of Health national Education Week. NCHE established a five-year cooperative agreement with the Centers for Disease Control and Prevention (CDC) Division of Adolescent and School Health (DASH) to develop youth and parent programming and community partnerships to help schools prevent health risk behaviors.

NCHE has an office in New York City, staff, and many graduate and undergraduate interns working on a variety of projects. Is there a potential to build on this structure in collaboration with the CNHEO and NCHEC? As I see it, there most certainly is!

The National Commission for Health Education Credentialing, Inc. was created in 1989 to improve the practice of health education and to serve the public and profession of health education by certifying health education specialists, promoting professional development, and strengthening professional preparation and practice. The major activities of NCHEC include: Developing and administering a national competency-based examination; developing standards for professional preparation; and promoting professional development through continuing education programs.

NCHEC has developed a process that is now familiar to almost all health educators and students. To become certified, candidates must show proof of their professional preparation and then pass the NCHEC nationally administered examination. The certification process was developed to attest to practitioners' knowledge and skills deemed necessary to the practice of health education as determined by the profession. Since 1989, approximately 9,000 individuals have been certified. The CHES credential must be renewed every year and recertification takes place every five years.

Requirements for recertification include the accrual of continuing education contact hours.

NCHEC has produced brochures promoting health education and certification and four books: (1) The Health Education Specialist: A Study Guide for Professional Competence Fourth Edition, Based on an original work by S. Deeds, Revised by J. Hayden.

(Allentown, PA: NCHEC, 2000): useful for aspiring and practicing health educators; (2) The Credentialing of Health Educators: An Historical Account 1970-1990 H. Cleary, (Allentown, PA: NCHEC, 1995): Dr. Cleary's personal account of the development of a credentialing system for health education specialists, the system now administered by The National Commission for Health Education Credentialing, Inc. (3) A Competency-Based Framework for Professional Development of Certified Health Education Specialists, (New York, NY: NCHEC, 1996): sets forth the standards of practice for health educators based upon seven areas of responsibility; (4) A Competency-Based Framework for Graduate-Level Health Educators, AAHE, NCHEC, \& SOPHE, (Allentown, PA: 


\begin{abstract}
NCHEC, 1999): a critical reference document which describes expanded areas of responsibility, competencies, sub-competencies, content descriptions, and objectives for graduate-level health educators.

NCHEC has an office in Pennsylvania, paid staff, and volunteer health education professionals on the Board of Directors and on the three divisions that address each of its purposes. Is the potential there to build on this structure, combining resources with NCHEO and NCHE? I'm sure there must be a way!
\end{abstract}

Figure \#2

Three Profession-wide Organizations: Perceived Strengths and Weaknesses

\section{Moving From Independence to Interdependence}

Let me gently suggest that perhaps part of the challenge is independence-bias. This "assumed attribute" may be precisely what is slowing us down. Independently it took us decades, yes decades, to get health education recognized by the federal government as a standard occupational category, recognition as a unique and essential profession with its own certification process, standards for undergraduate and graduate professional preparation program, a profession-wide code of ethics and research agenda, and a health education archives project.

Our independent organizations have their own mission statements, computerized administration systems and databases, journals, newsletters, web sites, grant application process, list servs, conferences, tasks forces, committees, etc. These resources and efforts are not coordinated or shared, resulting in redundant expenses and services during a time of scarce and dwindling resources. No one would say we ever planned to compete with each other, but the fact is, we do compete for the resources. Inter-organizational competition fosters what community organizers call "horizontal hostility" a condition usually fostered by those in power to keep marginalized groups preoccupied and divided - unable to achieve their common goals.

Why are we competing with each other when we could be collaborating? Given the major challenges the profession faces and the limited resources available, I think we must set aside the needs of individual organizations in favor of an agenda and organization that benefits the profession as a whole.

\section{If Not Us, Who? If Not Now, When?}

In the last three years, our goals and values as a profession have crystallized. We have identified and prioritized five focal areas for the profession: 1) creating synergy; 2) advocacy; 3) conducting, translating and disseminating research into dynamic and contemporary practice; 4) professional preparation and development and quality assurance; and (5) promoting and marketing the profession. We have just completed our precedent-setting Competencies Update Project study the findings from which should trigger important joint dissemination, translation, and health education marketing and promotion activities. We are in the process of establishing an academic program accreditation process. Our certification credential and process will soon celebrate its Sweet Sixteen. We have hundreds of undergraduate professional preparation programs available and dozens of graduate programs across the country. The number of health education and promotion journals has expanded with citations from our own and other professions increasing annually.

At the same time, in the past few years, some aspects of the finely woven fabric of our professional socialization have begun unraveling. Health departments are shutting down their health education bureaus and/or hiring staff other than trained and/or credentialed public health educators. College 
and university health education professional preparation programs and general service courses are being cut. National research in core areas such as human sexuality, have been cut back. Grant funds for what we consider essential health education services are being severely restricted or awarded with politically and emotionally charged strings attached. And finally, aspects of the profession are being claimed as new occupations or components of existing professions, thus whittling away at our only recently established federally recognized status.

\section{Doesn't Unification Make Sense?}

Doesn't it make sense to consolidate the time and money involved in maintaining almost a dozen separate organizations and to streamline how we do business and communicate with one another?

Doesn't it make sense to coordinate and achieve economies of scale in developing databases, service contracts, grant proposals, web sites, advocacy and media campaigns, train other professionals, network and communicate what health education and health educators are to a variety of audiences.

Doesn't is make sense to come together and form a single, centralized, financially stable health education organization to speak for the profession and to strategically plan and coordinate professional education, advocacy, marketing, communication, and networking activities... and anything else I may have missed?

Of course, there's no easy solution - but I am willing to stick my neck out and make a few proposals to trigger some debate, conversation, and perhaps....action.

\section{How about this:}

1. Let's form a Task Force to explore the feasibility of a single organization - besides the profession's "usual suspects" we might invite media representatives, funders, policy makers and consumers to participate - if not right away, eventually.
2. Let's assess our organizational assets and see what we have to share: procedures, policies, contracts, templates, handbooks ...anything.

3. Let's share resources - identify barters we can make with each other that are mutually beneficial.

4. Let's coordinate one major congress and conference and invite members of all our professional organizations. Anyone for Spring 2007 for the first-ever professionwide congress and conference in which we will all come together, in a tremendous show of pride and force to say, "Yes, we are all health educators; we all have common core competencies; we all support a common core health education agenda; and we are working together, as never before to advance health education in this country." It's not hard to envision such a conference: an opening congress in which organizational representatives would discuss administrative issues at the centralized and section levels, pre and/or post-conference information sessions on "hot" health education topics or skill-building workshops, daily opening plenary sessions on issues we all hold dear and a variety of daily open specialty track sessions.

5. Let's combine memberships. The outcome of such a congress could be the mobilization of health educators at large to rally around the centralized hub organization - increasing membership to at least half the 40,000 practitioners the Department of Labor tells us is out there. Clearly, I don't have all or even many of the answers or specific strategies, but perhaps we would then have a single membership that includes affiliation with 1 or 2 specialty sections.

6. Once we've proven we can work together and help each other, let's begin to look at which core management systems are strongest and see about centralizing them, making them available to all 14 agencies. For example, maybe if we all used the same continuing education tracking program or 
publisher we'd get a really sweet deal from the vendor instead of paying for four or five separate and more expensive contracts.

7. Then we can move toward centralizing all core services. We don't have to be literal about centralization: perhaps different organizations could run different systems; after all, in this day and age, a virtual centralized office is a strong option. In fact, I think that over the next few years, if we planned carefully, we could, using the electronic technology available, create at least a virtual central office with staff from different agencies working on core administrative services such as membership, continuing education, publications, grant proposals, etc. Under the direction/ guidance of this centralized office, specialty organizations would remain functional, on a smaller scale, focusing on specialty-specific projects but using shared, centralized databases and systems. Over the next two years, a table of organization and job descriptions could be developed and staff would have the option of applying for those positions or moving on, if they preferred.

\section{Next Steps}

"When all is said and done," some wit once quipped, "more is said than done." Let that not be true in our case!

Health educators have the knowledge and skill base that should make "building the elephant" very do-able. We know what it takes:

1. A single, common vision.

2. Clear, agreed upon operating beliefs and values.

3. Clear understanding of each organization's roles and responsibilities.

4. Collaboration, not cooperation.

5. A true partnership. We need to agree to be real partners with the responsibilities and accountabilities inherent in that role working toward an agreed upon goal.

6. The identification of specific steps necessary to take to get there.

7. Openness to a range of strategies and processes to move toward that vision.
8. Putting the profession first - before any single organization.

9. Organizational commitment.

10. Courage.

11. Leadership.

12. Financial support.

That said, how can we begin to practice what I preach? I'll begin by offering to put my money where my mouth is and challenge individuals and organizations to rise to the occasion. Here are two promises and two final recommendations:

First, at the first sign that the organizations are willing to begin to move in that direction I will make restricted donations and bequests to be used exclusively toward the development of a central office and centralized, standardized administrative policies, procedures, and practices.

Will you? I have no doubt that health educators all across the country will contribute to the establishment, finally, of the one, single, strong organization that will for once and for all strategically plan and coordinate marketing of the profession, advocacy priorities and efforts, continuing education programs and databases, research and practice grant applications, the translation of research findings into practice, and networking.

Second, I will do all I can to influence the organizations to which I belong to make a financial commitment from their reserves. We could start a fund raising challenge - each organization committing to donate a reasonable minimum figure - a percentage of the current budget? - over the next three years... and then more. I'd be willing to bet that most if not all of the 11 organizations representing health education have pots of money being saved for a rainy day - money they discuss how to spend eventually, if not right away. Here's one very practical use for it that will meet the need to market the profession for which our memberships have been clamoring.

Who will be the first organization to put up the first $\$ 50,000$ or $\$ 100,000$ toward a centralized 
administrative office coordinating the interdependent activities of a variety of specialty sections.

Our profession is blessed with a team of organizational leaders (executive directors, support staff, and volunteers) with an extraordinary combination of talents and skills. Together they and their organizations have a range of incredibly powerful assets and strengths...imagine the synergy! I call upon these extraordinary men and women to come together as soon as possible to lead the way.

Third, I propose two immediate actions. Let's contact our national organization(s)'s Executive Director(s) and, through their Web site "contact us" buttons, the leaders of the NCHEO, NCHE, and NCHEC and say, "I support unifying the profession through a single, centralized, streamlined, cost-saving, service-enhancing professional organizations. Please help make this happen.”

Maybe, if the emails start flying in support of unification, we can get that first meeting of executive directors scheduled right away and begin to talk about a profession-wide conference, and ultimately, a single centralized profession-wide marketing, research, fundraising, grant writing, advocacy, networking, professional development, and membership administrative body! Together, our leaders will help our profession come together to help us and those we need to have understand what the health education elephant really looks like! And the cry will be heard and taken up across the lands, "One for all, and all for one!"

\section{About the Author}

Karen Denard Goldman, PhD, CHES is a Brooklyn, N- based health education and social marketing consultant. She is the creator and co-author of the Health Promotion Practice column "Tools of the Trade," a past president of the Society for Public Health Education, co-founder of the New York State Coalition for Health Education, a former charter member of the National Center for Health Education, and a former member of the National Commission for Health Education Credentialing, Inc.

\section{References}

Capwell E (2004). Coalition of National Health Education Organizations, Californian Journal of Health Promotion 2(1): 12-15.

Cottrell, R. R., Girvan, J. T., \& McKenzie, J. F. (1999). Principles \& foundations of health promotion and education. Boston, MA: Allyn and Bacon.

National Commission for Health Education Credentialing, Inc. (2004). Home page. Retrieved November 17, 2004, from http://www.nchec.org/

National Center for Health Education. (2004). History. Retrieved November 17, 2004, from http://www.nche.org/nche about history.asp

Coalition of National Health Education Organizations. (2004). Home page. Retrieved November 17, 2004, from http://www.hsc.usf.edu/CFH/cnheo/

Author Information

Karen Denard Goldman, PhD, CHES, SPHR

Hlth Ed * Social Mkting * HR Development Consultant

Ph. 917-715-0928

E-Mail: rlgkdg@verizon.net 